\title{
Online Appreciation System for English Literature Based on Mobile Technology
}

\author{
Weiwei Qu \\ Teaching and Research Institute of Foreign Languages, Bohai University, Jinzhou, 121013, China \\ syquwei@yeah.net
}

Keywords: information technology; mobile technology; English literature; online appreciation; inverted index technology

\begin{abstract}
With the rapid development of information technology, the deep integration of information technology and English becomes the core of the current English learning. The rapid development of mobile technology brings much convenience in people's life, at the same time also brought new opportunity for English learning. In this paper, it uses mobile technology to develop English literature online appreciation system. First of all, simply introduces the basic concept of mobile technology; Secondly, the functional design is divided into two modules described in detail, including the front desk management module and the background management module; Finally, it using Inverted index technique based on Lucene to realize the Full-text search. The development and implementation of the system will help to stimulate the viewer's interest in learning, and improve the comprehensive ability to use English.
\end{abstract}

\section{Introduction}

With the increasingly frequent international exchanges, the development of the country and society has put forward higher requirements on College Students English ability [1], and need to strengthen the studying of the students' English comprehensive application ability, and that enjoy English literature also is an important aspect of improving the comprehensive application ability. Literature is the art form that which using language to express ideas and it can cultivate people's aesthetic ability. By the appreciation of literature, that you can understand foreign different way of life, enrich the cultural knowledge of learners, improve the ability of the learner's know and understand things. In English learning, learners appreciation outstanding literary works and encourage them to absorb the cultural essence of outstanding works, learning Western culture, finally comprehensively promote learners' English application ability and perception ability [2]. In recent years, that the digital learning with computer technology and network technology as the foundation, and mobile learning based on communication technology both bring a great influence on the current learning, it also bring revolution of the learning style and way of studying [3]. With the development of Internet technology and mobile technology, that its application in English literature appreciation to help the learners to appreciate English literature in his spare time, so that they fully understand the various aspects of knowledge. Mobile technology can support Learners learning whenever and wherever possible to use mobile devices. Mobile technology assisted language learning in the extended of learning time and space, rich interaction of learning, and improve learning efficiency and etc all have an unparalleled advantage.

\section{Mobile Learning}

Mobile Learning is a new concept, for how it is defined, so far there is not a unified and authoritative statement. In general, the definition of mobile learning can be respectively stressed from the technology point of view and emphasizes the ways of learning.

Defined in technical perspective

This view is supported by the majority of the current research literature, most researchers believe that the mobility is the basic characteristics of mobile learning, and it is a product of the combination of mobile technology and learning. The definition of Paul Harris is given: mobile 
learning is the intersection of mobile computing technology and E-learning, it can bring a whenever and wherever possible learning experience for learner, and make learning with rich interaction. Harris further explained this. He believes that mobile learning should be able to make learners enjoy a learning piece through a mobile phone or PDA anytime and anywhere. Literature [4] think mobile learning is that student can carry out no matter when and where learning based on mobile and portable equipment rather than by physical communication equipment(Including wireless, wired communication mode: online and offline mobility) which permanently wired network interconnection.

Defined in learning perspective

In other studies, researchers found that mobile learning should not just stop at the device level, and more should discuss the learning styles change that mobile learning can bring to the learners. The literature [5] think that mobile learning is according to their own needs, then using the wireless networks and mobile learning devices for learning, and the realization of their own construction of knowledge in the process, so that the external information internalized as their own knowledge.

To sum up, the definition of mobile learning should include two basic connotations of the following:

(1) The occurrence of mobile learning is based on the support of wireless mobile communication network technology and a wireless mobile communication device (such as mobile phone, personal digital assistant PDA, Pocket PC etc.).

(2) The characteristics of mobile learning are learning convenience, personalized learning, interaction richness and situational relevance etc.

Mobile learning is that learners use mobile devices, through the mobile communication network, to carry out learning activities at any time and place, it also known as 4A-free learning(Anyone, Anytime, Anywhere, Any style). With the growing of computer processing power and the rapid development of mobile communication technology, that mobile technology in all sectors of business applications will be widely spread. The rapid development of computer technology, network technology, and database technology promoted the rapid development of computer of mobile technology, now mobile technology has a certain application in various fields.

\section{System Structure Design}

$\mathrm{B} / \mathrm{S}$ structure is a Web-based network platform model. The system uses multi-tier architecture based on $\mathrm{B} / \mathrm{S}$, which is shown in Fig. 1 [6,7].

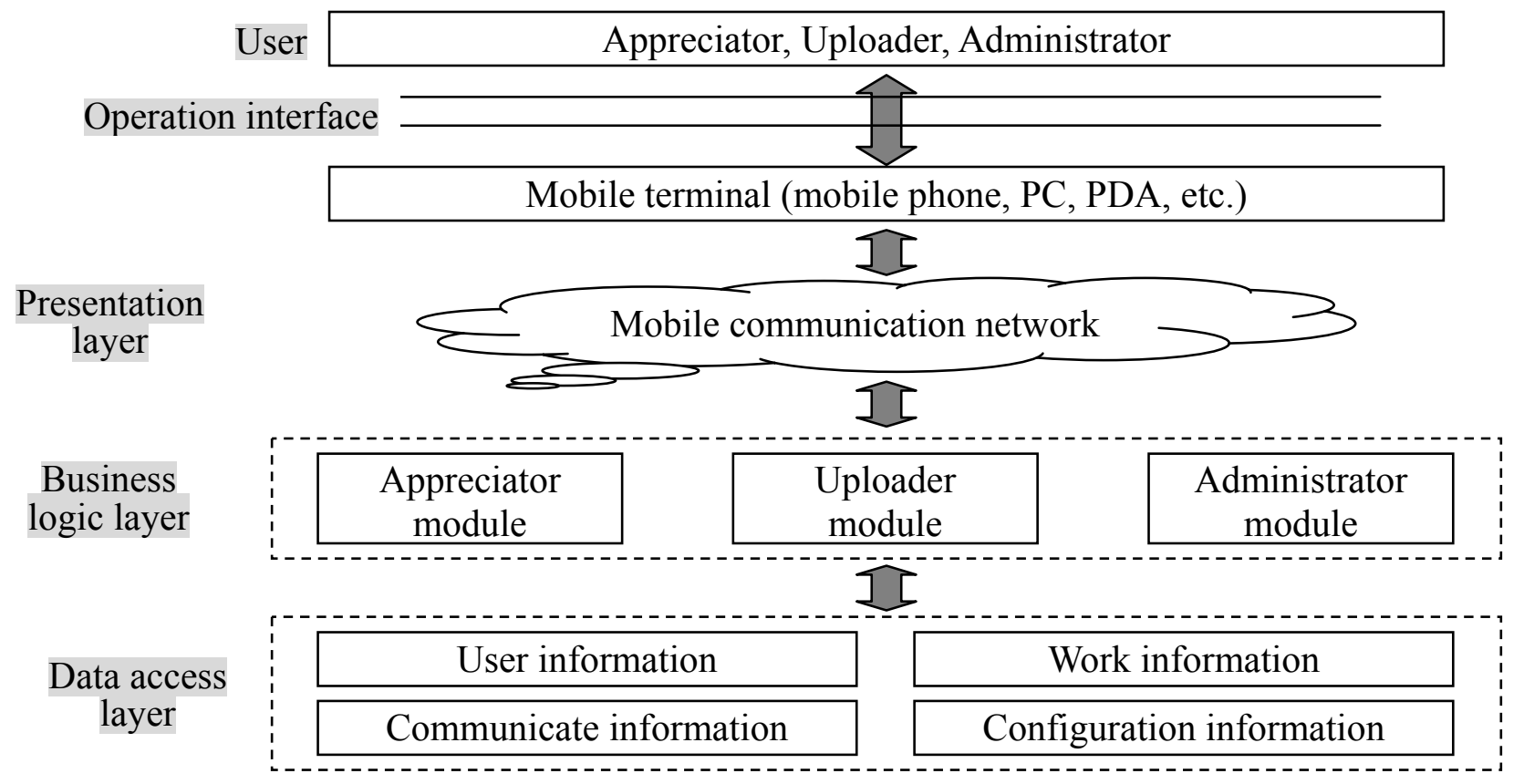

Fig. 1. System structure 
(1) Presentation layer is mainly responsible for accepting users' requests and returning data to provide client with access to applications. The presentation layer structure reflects the human-machine interface, including preparation for the processing of data logic. Specifically, it is to manage a variety of form objects, test data reasonableness, search between different form objects and process error messages of expression logic. It is also responsible for organizing data obtained from read transaction into graphs, charts and other display formats according to the needs of from the end-users.

(2) Business logic layer is mainly responsible for the operation of the data layer that is combining some operations of data layer. Business logic layer is the core of the system architecture, which focuses on the system design concerned with business needs, such as the constitution of business rules and the achievement of business processes, so it relates to domain logic coping with system. Business logic layer is in the middle between data access layer and presentation layer in the architecture, playing a connecting role in data exchange.

(3) Data access layer is the operation layer for original data (database or text files and other forms of data storage), rather than the original data, that is, it is the operation for the data, rather than the database, specifically provide data services for business logic layer or presentation layer. Simply say is to achieve Select, Insert, Update, Delete operation for the data tables.

\section{Function Module Design}

In view of two users of using the software, the function module design is divided into two parts: one is the front desk management module, and the other is a background management module. In front of the management module mainly targeted at members of the user, the function module diagram is shown in Fig. 2; the background management module mainly for the administrator, the function module diagram is shown in Fig. 3.

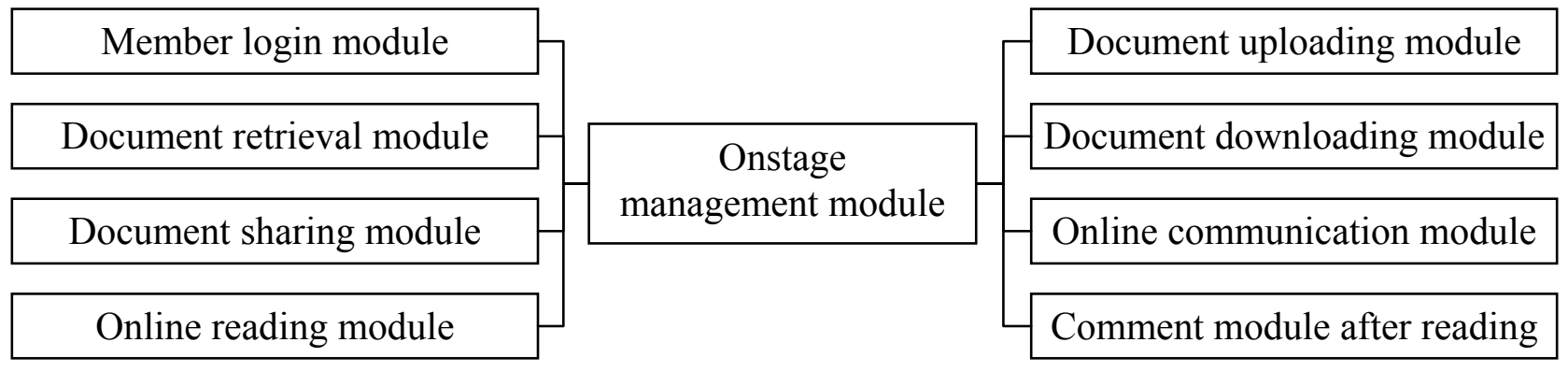

Fig. 2. Function module chart of onstage

In the front office management module, mainly includes eight function modules, below are the details about the function of the eight modules. 1 Member login module: the user is divided into ordinary user and a member of the user, members need to login system to carry out a series of operations. In the login module, member input your account number and password, if the input is correct that you will enter in the home side; if the input is error, then continue to stay in the login page to continue login until a successful login. everyday each account is only three chances to enter the wrong account and password, the account will be frozen after three times, the next automatic defrost; 2 document retrieval module: the user can according to need to retrieve articles which they want to see, then system according to the input keyword search the articles from the database for user to see, and down in order of priority according to the size of the correlation. Members and ordinary users all can do this; 3 document sharing module: this module is only for members, that if member login success, then can collect their favorite articles and share it with other users; 4 online reading module: connect to the Internet, all browse this system people can appreciate the literary works through the online system; 5 document uploading module: this module is only for the membership user, members can be their own articles which on their mobile device to upload to the system to increase the value of their points, so they can download more files; 6 document downloading module: this module is only for members of the user, after logging into their account, in accordance with the need to download files; 7 online communication module: when read the 
article, that the questions or thoughts can be real-time and online communication; 8 comment module after reading: after reading the article, you can publish your thoughts in the comments for others to reference.

\begin{tabular}{|l|l|l|}
\hline Administrator login module & Auditing information module \\
\hline Member management module & $\begin{array}{c}\text { Backstage } \\
\text { Document management module }\end{array}$ & Recommending module \\
\cline { 3 - 3 } & Document uploading module \\
\hline
\end{tabular}

Fig. 3. Function module chart of backstage

In the background management module mainly includes six function modules, and the following describes the functions of the six modules. 1 Administrator login module: system administrators need to $\log$ in to manage operations. In the login module, the administrator enter their account number and password, if the input is correct then enter the administration page; if the input is error, then continue to stay in the login page to continue login until a successful login; 2 membership management module: the administrator after the successful landing that they can view, modify, and delete the basic information of members; 3 document management module: the administrator after the successful landing, when after clicking on "File Management" then the article of the database can be add, modify, and delete. When you add the article, you need to add the authors, writing time, and type of information to help readers understand the article; 4 auditing information module: when new user registration, administrators need to review that whether the user information is legitimate, if legitimate, new user registration is successful, otherwise delete user information. For the members submitted information, administrators also need to review, delete the illegal comment, and inform the user comments; 5 recommending module: for a new article or read a large quantity of articles, or user evaluation good article, administrators can recommend to the user in the news; 6 document uploading module: administrators can upload articles.

\section{Inverted Index Technology}

Inverted index, also known as reverse index or reverse archives, is used to store a keyword's map of storage location in a document, or some documents under the full-text search, it is a common indexing method [8]. In order to achieve fast retrieval, the paper uses inverted index technology based on Lucene to achieve full-text retrieval. Lucene is a full-text search engine toolkit of open source codes, and it also is architecture of full-text search engine, which provides a complete query engine and index engine. System model of full-text retrieval is shown in Fig. 4.

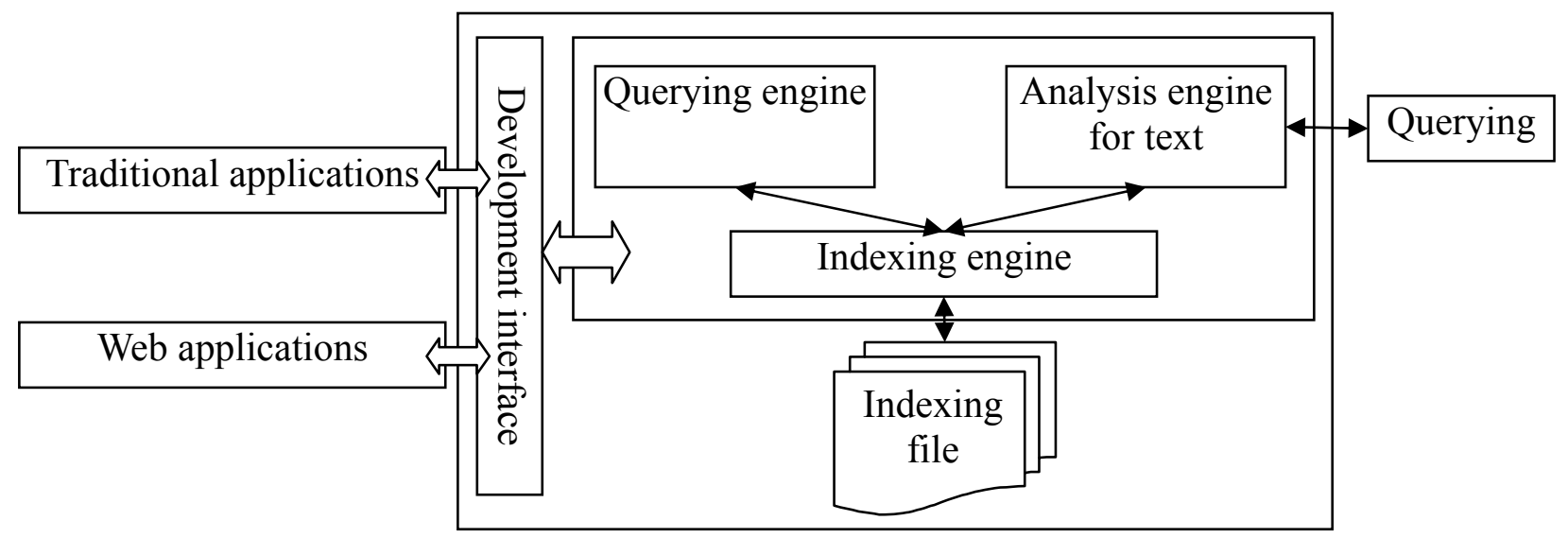

Fig. 4. System model of full text retrieval

The indexing process mainly includes three parts:

(1) Pre-processing stage: indexing for document data in order to use Lucene, the document should be converted to the type that Lucene can handle; 
(2) Analysis stage: data can be passed to the Lucene to conduct indexing operation by calling addDocument (Document) method. Lucene analyzes the data at first and then makes it more suitable to be indexed. Document class is used to describe the document;

(3) Write to index: after analysing the input data, the results are written to the index file, the input data is stored as the data structure of inverted index.

\section{Conclusion}

Resources of mobile appreciation English literature are provided by the online environment, viewers need to use computers, mobile phones, netbooks, PDA, laptops or tablet computers and other wireless devices and mobile QQ, SMS and mobile email and other online group collaboration tools to browse literary works, and then participate in discussion of forums [9]. According to the individual needs, viewers can select time freely, and the contents of the system and the overall appreciation activities can be split to appreciate in a piecemeal way [10]. The study of the project paves the way for mobile devices and mobile resources that can be better used in the field of learning, it also shows that the development and application of mobile learning and appreciation platform has a broad prospects, which lay the foundation for the construction of the English mobile learning resource network. The system not only can improve learner's appreciation level of literature, but also it can increase comprehensive application ability of English.

\section{Acknowledgement}

This work is supported by "2014 Economic and Social Development Project of Liaoning Provincial Federation Social Science Circles" (2014lslktjyx-04).

\section{References}

[1] J. Zhang, "Study of Hybird Audio-Lingual Model in College English Teaching With the Support of Mobile Technology," Doctor's degree of Northeast Normal University, 2011.

[2] M. R. Qi, "Importance of English Literature Appreciation in English Learning," New West, vol. 15, no. 20, pp. 152, 2014.

[3] D. S. Wang, "Ubiquitous learning of English Supported by Mobile Technology," China Educational Technology \& Equipment, vol. 28, no. 20, pp. 143-144, 2014.

[4] Z. P. Hu, "The Impact of 3G Technology to Mobile Phone Studying," Chinese Technology Expo, vol. 12, no. 20, pp. 20-23, 2010.

[5] J. Huang, "A Study of English Strategy Based on Mobile Learning," China Educational Technique \& Equipment, vol. 23, no. 21, pp. 139-141, 2009.

[6] X. Peng, Z. Ping, "Construction Scheme of University Scientific Research Man-agement Platform Based on MVC Model," Computer Technology and Development, vol. 23, no. 4, pp. 249-253, 2013.

[7]

Baidu pictures, "Mobile Learning," http://image.baidu.com/search/detailm\%2Fupload\%2ukd1819ndjlk1nwc9ll\&gsm=0, 2015-9-1.

[8] C. C. Dong, "Study on Hadoop-based Inverted Index," Master's degree of Liaoning University, 2011.

[9] Y. W. Yang, "An Empirical Study on Integration of Mobile Technologies into Distance English Teaching Environment," Distance Education in China, vol. 32, no. 2, pp. 26-32, 2012.

[10] R. Y. Liu, "The Concept and Strategy of English Mobile Learning of Junior High School," Fujian Basic Education Study, vol. 14, no. 7, pp. 79-80, 2014. 